\title{
Exosome-mediated gefitinib resistance in lung cancer HCC827 cells via delivery of miR-21
}

\author{
CHANGWEN JING $^{1 *}$, HAIXIA CAO $^{1 *}$, XIAOBING QIN $^{2}$, SHAORONG YU $^{3}$, \\ JIANZHONG WU ${ }^{1}$, ZHUO WANG $^{1}$, RONG MA ${ }^{1}$ and JIFENG FENG ${ }^{3}$
}

\begin{abstract}
${ }^{1}$ Clinical Cancer Research Center, Jiangsu Cancer Hospital, Cancer Institute of Jiangsu Province, The Affiliated Cancer Hospital of Nanjing Medical University; ${ }^{2}$ The Fourth Clinical School of Nanjing Medical University, Nanjing Medical University; ${ }^{3}$ Department of Chemotherapy, Jiangsu Cancer Hospital, Cancer Institute of Jiangsu Province,

The Affiliated Cancer Hospital of Nanjing Medical University, Nanjing, Jiangsu 210009, P.R. China
\end{abstract}

Received January 17, 2017; Accepted October 26, 2017

DOI: $10.3892 / \mathrm{ol} .2018 .8604$

\begin{abstract}
Acquired resistance to gefitinib remains a major challenge in cancer treatment. In the present study, the effect of exosomes on the transmission of gefitinib resistance from gefitinib-resistant HCC827 lung cancer cells (H827R) to their gefitinib-sensitive counterparts and the potential underlying mechanisms by which this occurs was investigated. Exosomes were obtained from the cell supernatant using ultracentrifugation and the ExoQuick-TC exosome precipitation solution. Drug resistance was assessed by flow cytometry, apoptosis assays and cell counting kit-8 assays. The expression of microRNA (miR)-21 was analyzed by reverse transcription-quantitative polymerase chain reaction. Exosomes released by H827R cells (R/exo) may decrease the sensitivity of the human NSCLC HCC827 cell line to gefitinib. The results indicated that miR-21 expression was increased in R/exo and R/exo-treated H827S cells. However, miR-21 inhibition abrogated exosome-mediated drug resistance. Phosphorylated-protein kinase B (p-Akt), which is downstream of miR-21, was downregulated following gefitinib treatment; however, R/exo pretreatment elevated p-Akt levels and promoted the activation of Akt. By contrast, miR-21 inhibition reduced p-Akt expression. Therefore, the induction of miR-21
\end{abstract}

Correspondence to: Dr Rong Ma, Clinical Cancer Research Center, Jiangsu Cancer Hospital, Cancer Institute of Jiangsu Province, The Affiliated Cancer Hospital of Nanjing Medical University, 42 Baiziting Road, Nanjing, Jiangsu 210009, P.R. China E-mail: ailuo06@126.com

Dr Jifeng Feng, Department of Chemotherapy, Jiangsu Cancer Hospital, Cancer Institute of Jiangsu Province, The Affiliated Cancer Hospital of Nanjing Medical University, 42 Baiziting Road, Nanjing, Jiangsu 210009, P.R. China

E-mail: fjif@vip.sina.com

${ }^{*}$ Contributed equally

Key words: non-small cell lung cancer, gefitinib resistance, exosomes, microRNA-21 via exosomes and the activation of Akt may be mechanisms by which exosomes mediate the transfer of drug resistance.

\section{Introduction}

Lung cancer is the primary cause of cancer-associated mortality worldwide and non-small cell lung cancer (NSCLC) is the most common histological type of lung cancer. Despite advances in treatment, the 5-year survival rate of patients with NSCLC remains poor, at $<15 \%$ (1).

Over the past few decades, epidermal growth factor receptor-tyrosine kinase inhibitors (EGFR-TKIs), such as gefitinib, have been the most widely used targeted therapy to treat patients with lung cancer worldwide and have significantly improved the overall survival rate of lung cancer $(2,3)$. However, some patients develop resistance to gefitinib following an initial period of treatment (4). It has been determined that acquired gefitinib resistance is primarily linked to a T790M mutation, hepatocyte growth factor receptor or insulin-like growth factor 1 receptor gene amplifications or abnormalities of the phosphatase and tensin homolog (PTEN) and mechanistic target of rapamycin (mTOR) proteins (5). Other reasons responsible for the development acquired gefitinib resistance remain unknown; the underlying mechanisms behind what causes this resistance to develop are yet to be elucidated.

Exosomes are small extracellular membrane vesicles 40-100 $\mathrm{nm}$ in diameter, which are secreted by a wide range of cells (6). Exosomes contain a substantial amount of RNA and may be transferred from one cell to another, thereby contributing to tumor growth, metastasis, angiogenesis and drug resistance $(7,8)$. Exosomes from drug-resistant breast cancer cells (MCF-7/DOC) may transfer resistance to sensitive cells (MCF-7/S) (9). In the presence of exosomes extracted from drug-resistant cells (DOC/exo), MCF-7/S developed drug resistance, which did not occur in cells exposed to their own exosomes (S/exo) (9). It has been reported that, following the release of exosomes by NSCLC A549 cells during cisplatin stimulation, the sensitivity of A549 cells to cisplatin was decreased; this process may have been mediated by the exchange of microRNAs (miRNA) and mRNAs between exosomes via cell-to-cell communication (10). 
To the best of our knowledge, the involvement of exosomes in the development of resistance to gefitinib in lung cancer cells remains unknown. In the present study, the effect of exosomes on the transmission of gefitinib resistance from gefitinib-resistant HCC827 lung cancer cells to their gefitinib-sensitive counterparts was investigated and the potential underlying mechanisms by which this may occur was explored.

\section{Materials and methods}

Reagents and cell culture. Gefitinib (Iressa ${ }^{\circledR}$ ) was purchased from AstraZeneca plc. (Cambridge, UK). The human NSCLC cell line HCC827, which is sensitive to gefitinib and referred to in the current study as H827S, containing an EGFR exon19 deletion (DelE746-A750) was obtained from the Cell Resource Center of the Shanghai Institutes for Biological Sciences of the Chinese Academy of Sciences (Shanghai, China). A gefitinib-resistant cell line (H827R) was generated in the laboratory and individual H827R-7-1 clones were isolated from single cell clone of parental H827R cells using the method of maximum dose dilution as described previously (11).

Cells were cultured in RPMI-1640 medium (Invitrogen; Thermo Fisher Scientific, Inc., Waltham, MA, USA) with 10\% exosome-depleted fetal bovine serum (Gibco; Thermo Fisher Scientific, Inc.), $100 \mathrm{U} / \mathrm{ml}$ penicillin and $50 \mu \mathrm{mol} / \mathrm{l}$ $\beta$-mercaptoethanol (Sigma-Aldrich; Merck KGaA, Darmstadt, Germany). All cell cultures were maintained in an incubator containing $5 \% \mathrm{CO}_{2}$ at $37^{\circ} \mathrm{C}$. The resistant $\mathrm{HCC} 827$ cells were passed $\leq 15$ times in the absence of gefitinib to maintain their resistance.

Exosome isolation and confirmation. Exosomes from the supernatants of H827S and H827R-7-1 cells were designated as $\mathrm{S} / \mathrm{exo}$ and $\mathrm{R} / \mathrm{exo}$, respectively. The cell supernatant was centrifuged at $1,000 \mathrm{x} \mathrm{g}(10 \mathrm{~min}), 10,000 \mathrm{x} \mathrm{g}\left(30 \mathrm{~min}\right.$ at $\left.4^{\circ} \mathrm{C}\right)$, and $100,000 \times \mathrm{g}\left(120 \mathrm{~min}\right.$ at $\left.4^{\circ} \mathrm{C}\right)$ using a Beckman ultracentrifuge (AvantiJ-30I; Beckman Coulter, Inc., Brea, CA, USA ). The final pellets were resuspended in ExoQuick-TC exosome precipitation solution (System Biosciences, Mountain View, CA, USA) overnight at $4^{\circ} \mathrm{C}$ and were centrifuged at $1,500 \mathrm{x} \mathrm{g}\left(30 \mathrm{~min}\right.$ at $\left.4^{\circ} \mathrm{C}\right)$. The extracted pellets were diluted in $200 \mu \mathrm{l}$ of PBS and stored at $-80^{\circ} \mathrm{C}$. Exosomes were observed using a JEM-2100 transmission electron microscope (TEM; JEOL, Ltd., Tokyo, Japan). Exosomes were quantified using an enhanced BCA protein assay kit (Beyotime Institute of Biotechnology, Haimen, China).

Reverse transcription-quantitative polymerase chain reaction $(R T-q P C R)$. Exosomal RNAs were isolated using a mirVana ${ }^{\mathrm{TM}}$ miRNA Isolation kit (Invitrogen; Thermo Fisher Scientific, Inc.) following the manufacturer's protocol. Total cellular RNA was extracted using TRIzol (Life Sciences; Thermo Fisher Scientific, Inc.).

The Bulge-Loop ${ }^{\text {TM }}$ hsa-miR-21 RT-qPCR primer set and U6 small nuclear (sn)RNA RT-qPCR primer sets (both 100T) were purchased from Guangzhou RiboBio Co., Ltd. (Guangzhou, China). miRNA was stem-loop reverse transcribed using a PrimeScript ${ }^{\mathrm{TM}}$ 1st Strand cDNA Synthesis kit (Takara Bio, Inc., Otsu, Japan). qPCR was performed using a TaqMan ${ }^{\mathrm{TM}}$ miRNA assay kit according to the manufacturer's protocol on an ABI 7300 detection system (Applied Biosystems, Foster City, CA, USA). A gene-specific probe mix (miR-21, 000397) was utilized. U6 was used as the internal control. The $2^{-\Delta \Delta \mathrm{Ct}}$ method was used to determine the fold change of miR-21 (12).

Experimental groups. To investigate whether R/exo induced gefitinib-resistance in susceptible cells, 6 groups were prepared as follows: Control (H827S without exosome and gefitinib treatment), H827S+gefitinib (H827S incubated with $50 \mathrm{nM}$ gefitinib), H827S+S/exo (H827S pretreated with S/exo for $24 \mathrm{~h}$ ), H827S+S/exo+gefitinib (H827S pretreated with S/exo for $24 \mathrm{~h}$ and incubated with $50 \mathrm{nM}$ gefitinib for a further $48 \mathrm{~h}$ ), H827S+R/exo (H827S pretreated with R/exo for $24 \mathrm{~h}$ ), $\mathrm{H} 827 \mathrm{~S}+\mathrm{R} / \mathrm{exo}+$ gefitinib (H827S pretreated with R/exo for $24 \mathrm{~h}$ and incubated with $50 \mathrm{nM}$ gefitinib for a further $48 \mathrm{~h}$ ). The viability and apoptotic rates of cells in each group were measured following the aforementioned treatments to assess the effect of R/exo on the cells.

Transfection. The Hsa-miR-21 inhibitor, 5'-UCAACA UCA-GUCUGAUAAGCUA-3' and the negative control (NC), 5'-CAGUACUUUUG-UGUAGUACAA-3' small interfering (si)RNAs were obtained from Shanghai GenePharma Co., Ltd. (Shanghai, China).

The following groups were designed to assess the effect of miR-21 on exosome mediated drug resistance: $\mathrm{H} 827 \mathrm{~S}+\mathrm{NC}$ siRNA+S/exo (H827S transfected with NC siRNA and pretreated with S/exo for $24 \mathrm{~h}$ without gefitinib treatment), H827S+NC siRNA+S/exo+gefitinib (H827S transfected with NC siRNA, pretreated with S/exo for $24 \mathrm{~h}$ and stimulated with $50 \mathrm{nM}$ gefitinib for a further $48 \mathrm{~h}$ ), H827S+NC siRNA+R/exo+gefitinib (H827S transfected with NC siRNA, pretreated with R/exo for $24 \mathrm{~h}$ and stimulated with $50 \mathrm{nM}$ gefitinib for a further $48 \mathrm{~h}$ ), H827S+miR-21 siRNA+R/exo+gefitinib (H827S transfected with miR-21 siRNA, pretreated with R/exo for $24 \mathrm{~h}$ and stimulated with gefitinib for a further $48 \mathrm{~h}$ ).

Oligonucleotides $(50 \mathrm{nM})$ were transfected into $\mathrm{H} 827 \mathrm{~S}$ cells that had reached $70 \%$ confluence using Lipofectamine ${ }^{\circledR} 2000$ (Invitrogen; Thermo Fisher Scientific, Inc.) following the manufacturer's protocol. Following $24 \mathrm{~h}$ transfection, R/exo or S/exo were added to the corresponding wells. Following another $24 \mathrm{~h}$, cells were exposed to 0 or $50 \mathrm{nM}$ gefitinib for $48 \mathrm{~h}$ at $37^{\circ} \mathrm{C}$ prior to being harvested for cell viability assay and flow cytometry analysis, following the protocols described below.

Cell viability assay. H827S cells were plated into 96-well plates at a density of $\sim 5,000$ cells/well. Following $24 \mathrm{~h}$ incubation, S/exo or R/exo were added to the cells for $24 \mathrm{~h}$ at $37^{\circ} \mathrm{C}$. The same volume of PBS without exosomes was added to cells in the control group. Cells were exposed to 0 or $50 \mathrm{nM}$ gefitinib for $48 \mathrm{~h}$ at $37^{\circ} \mathrm{C}$ and cell viability was subsequently assessed using a cell counting kit-8 (CCK-8; Dojindo Molecular Technologies, Inc., Kumamoto, Japan) according to the manufacturer's protocol.

Sensitivity test. Growth inhibition was measured by CCK-8 assay. Briefly, the cells were plated onto 96 -well plates at a 
density of approximately 5,000 cells per well and exposed to a concentration gradient of gefitinib $(0,10,50,100,500 \mathrm{nM}$, 1,5 and $10 \mathrm{mM}$ ) for $48 \mathrm{~h}$. This test was carried out to confirm the successful establishment of H827R.

Flow cytometry. H827S cells were seeded and cultured in 6 -well plates at a concentration of $1 \times 10^{6}$ cells/well. H827S cells were incubated with S/exo or R/exo for $24 \mathrm{~h}$ and subsequently treated with either 0 or $50 \mathrm{nM}$ gefitinib for a further $48 \mathrm{~h}$ at $37^{\circ} \mathrm{C}$. The cells were then stained using a fluorescein isothiocyanate Annexin V apoptosis detection kit (BD Biosciences, Franklin Lakes, NJ, USA) and BD Accuri C6 flow cytometer (BD Biosciences) and BD Accuri C6 Software (version 1.1.264.21; BD Biosciences) was used to discriminate apoptotic cells. At least 10,000 cells were analyzed for each group.

Western blot analysis. Harvested cells were lysed with an ice-cold lysis buffer containing $50 \mathrm{mmol} / 1$ Tris- $\mathrm{HCl}$ ( $\mathrm{pH} 7.4$ ); $1 \% \mathrm{NP}-40 ; 150 \mathrm{mmol} / 1 \mathrm{NaCl} ; 1 \mathrm{mmol} / 1$ EDTA; $1 \mathrm{mmol} / \mathrm{l}$ phenylmethylsulfonyl fluoride and complete proteinase inhibitor mixture (one tablet per $10 \mathrm{ml}$; Roche Molecular Diagnostics, Pleasanton, CA, USA). Protein content was determined using a DC Protein Assay kit (Bio-Rad Laboratories, Inc., Hercules, CA, USA) and western blot analysis was performed following a previously described protocol (10). Individual immunoblots were probed with antibodies against phosphorylated (p)-protein kinase B (Akt; Ser473; D9E) $\mathrm{XP}^{\circledR}$ rabbit mAb (cat. no. 4060S; dilution 1:1,000), Akt (pan; C67E7) rabbit mAb (cat. no. 4691S; dilution 1:1,000; both Cell Signaling Technology, Inc., Danvers, MA, USA) and $\beta$-actin polyclonal antibodies (cat. no. AP0060; dilution 1:2,000; Bioworld Technology, Inc., St. Louis Park, MN, USA) at $4^{\circ} \mathrm{C}$ overnight and finally with a horseradish peroxidase-conjugated antibody (cat no. 7074S; dilution 1:2,000; Cell Signaling Technology, Inc.) at room temperature for $1 \mathrm{~h}$. Proteins were visualized using an enhanced chemiluminescence solution (Life Sciences; Thermo Fisher Scientific, Inc.).

Statistical analysis. Statistical analysis was performed with SPSS software (version 20.0; IBM Corp., Armonk, NY, USA). Comparisons between pairs were performed using a Student's t-test and multiple comparisons between the groups were analyzed using one-way analysis of variance followed by a Student Newman-Keuls test. All experiments were performed three times and the results are presented as the mean \pm standard deviation. $\mathrm{P}<0.05$ was considered to indicate a statistically significant difference.

\section{Results}

Exosomes contribute to gefitinib resistance in NSCLC H827S cells. The inhibitory concentrations for $50 \%$ cell death $\left(\mathrm{IC}_{50}\right)$ values of gefitinib were $>10 \mu \mathrm{M}$ for $\mathrm{H} 827 \mathrm{R}$ and $0.05 \mu \mathrm{M}$ for $\mathrm{H} 827 \mathrm{~S}$, thus identifying gefitnib resistance in H827R cells (data not shown). Following exosome isolation from the cell supernatant of H827S and H827R cells, residual vesicles were observed using TEM (Fig. 1A). The diameter of the vesicles was $<100 \mathrm{~nm}$, indicating that exosomes were successfully extracted.

Compared with the control group (100\%), cell viability was $95.3 \pm 1.1,95.7 \pm 4.5,50.4 \pm 1.9,50.7 \pm 2.1$ and $67.5 \pm 1.8 \%$ in the $\mathrm{H} 827 \mathrm{~S}+\mathrm{S} / \mathrm{exo}, \mathrm{H} 827 \mathrm{~S}+\mathrm{R} / \mathrm{exo}, \mathrm{H} 827 \mathrm{~S}+$ gefitinib, $\mathrm{H} 827 \mathrm{~S}+\mathrm{S} /$ exo+gefitinib and H827S+R/exo+gefitinib groups, respectively (Fig. 1B). Pretreatment with R/exo significantly increased H827S cell viability following gefitinib stimulation compared with untreated and S/exo treated H827A cells. Cells were analyzed using flow cytometry (Fig. 1C) and the results of the apoptosis assay were similar to those of the CCK-8 assay. The apoptosis rates were $3.2 \pm 0.3,3.7 \pm 0.3,3.6 \pm 0.5$, $44.3 \pm 2.0,44.8 \pm 0.7$ and $27.9 \pm 1.4 \%$ in the H827S, H827S+S/exo, H827S+R/exo, H827S+gefitinib, H827S+S/exo+gefitinib and $\mathrm{H} 827 \mathrm{~S}+\mathrm{R} /$ exo+gefitinib groups, respectively (Fig. 1D). Treatment with R/exo prior to gefitinib exposure significantly decreased the sensitivity of H827S cells to gefitinib compared with the cells pretreated with S/exo. Cell viability and rates of apoptosis did not differ significantly between the H827S and H827S+S/exo groups. These results indicate that exosomes released by $\mathrm{H} 827 \mathrm{R}$ cells may decrease the sensitivity of $\mathrm{H} 827 \mathrm{~S}$ cells to gefitinib, whereas exosomes released by $\mathrm{H} 827 \mathrm{~S}$ cells have little influence on the sensitivity of H827S cells to gefitinib.

miR-21 expression is increased in R/exo and R/exo-treated $H 827 \mathrm{~S}$ cells. miRNAs are a class of small non-coding RNAs 18-25 nucleotides in length; these molecules post-transcriptionally inhibit gene expression by inducing degradation or blocking translation of miR targets (13). miR-21 is overexpressed in several human malignancies and has been implicated in various biological processes, including cell proliferation, apoptosis, invasion and metastasis (14). Evidence has emerged regarding the role of miR-21 in the regulation of drug resistance (15-17) and miR-21 overexpression is associated with the development of gefitinib resistance in NSCLC (18). To determine the involvement of miR-21 in exosome-mediated gefitinib resistance, RT-qPCR was performed to measure the expression of miR-21 in H827 cells. H827S and H827R-7-1 cells were seeded and cultured in 6 -well plates for $48 \mathrm{~h}$. Cells then underwent RT-qPCR and the results demonstrated that miR-21 expression was significantly increased in H827R-7-1 cells by 2.46 \pm 0.15 -fold compared with H827S cells (Fig. 2A).

For exosome isolation, H827S and H827R-7-1 cells were seeded in $15-\mathrm{cm}$ plates for $48 \mathrm{~h}$ and exosomes were subsequently obtained. The H827S cells were incubated with either S/exo or R/exo for 24 h. miR-21 expression was significantly increased in the R/exo group by $2.56 \pm 0.08$-fold compared with the S/exo group (Fig. 2B). In addition, miR-21 expression was significantly increased in R/exo-treated H827S cells by 2.28 \pm 0.12 -fold compared with $\mathrm{H} 827 \mathrm{~S}$ cells pretreated with S/exo (Fig. 2C).

miR-21 inhibition attenuates exosome-mediated drug resistance. To elucidate the role of miR-21 in the ability of $\mathrm{R} /$ exo to increase cell viability and inhibit cell apoptosis in NSCLC cells, miR-21 expression was inhibited (Fig. 3). H827S cells were transfected with anti-miR-21 or NC siRNA. Following $48 \mathrm{~h}$ treatment, miR-21 expression was measured using RT-qPCR. The results demonstrated that miR-21 expression was significantly downregulated in cells transfected with the miR-21 siRNA compared with cells transfected with NC siRNA (Fig. 3A). 


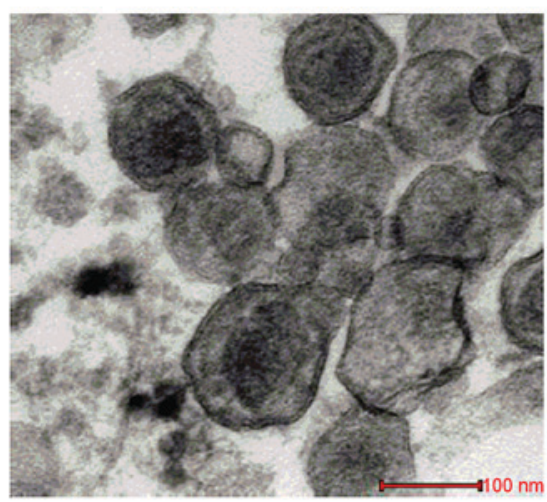

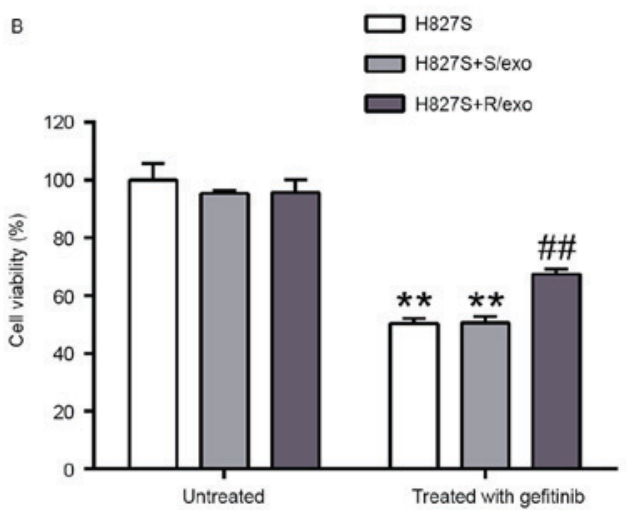

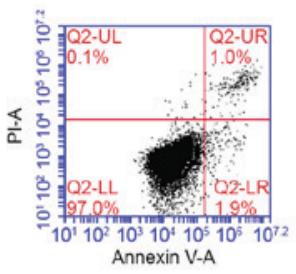

H827S
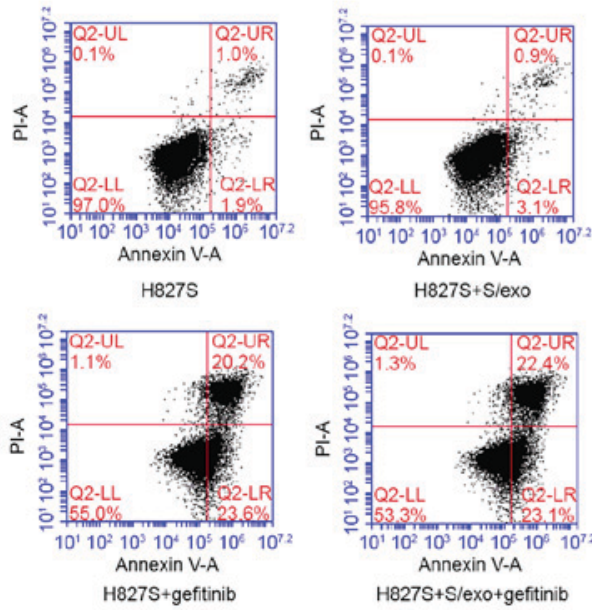

Annexin V-A

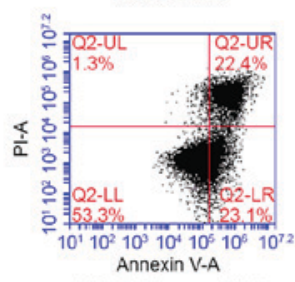

H827S+S/exo+gefitinib
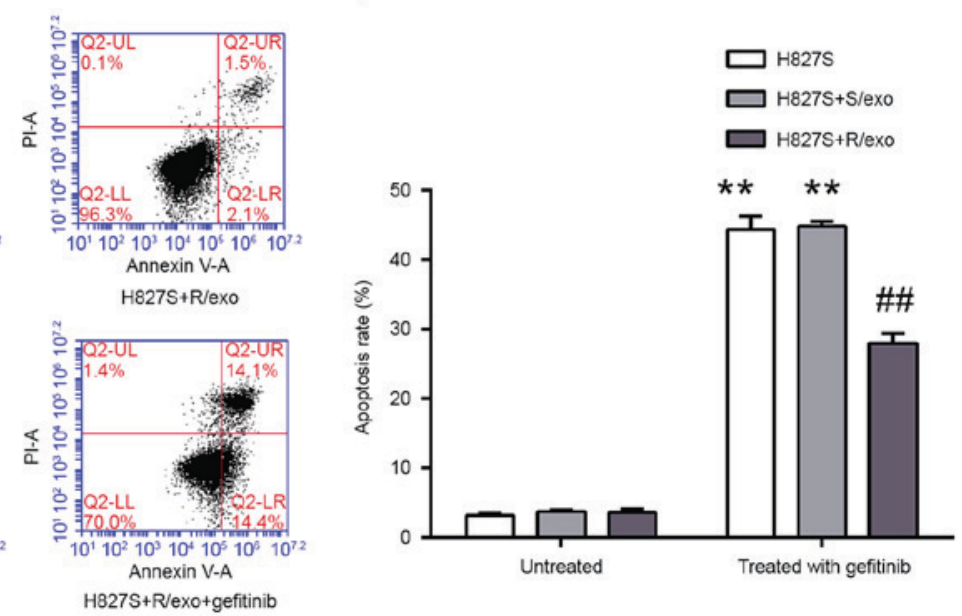

Figure 1. Influence of R/exo on the sensitivity of H827S cells to gefitinib. (A) Transmission electron microscopy image of exosomes. (B) Following stimulation with or without $50 \mathrm{nM}$ gefitinib for $48 \mathrm{~h}$, cell viability was determined using a cell counting kit- 8 assay. (C) Cells were harvested for flow cytometry analysis and flow cytometry graphs are representative of three separate experiments. (D) The apoptosis rate was determined. ${ }^{* *} \mathrm{P}<0.01$ vs. the untreated group; ${ }^{\# \#} \mathrm{P}<0.01$ vs. the H827S+S/exo+gefitinib group. S/exo, exosomes from H827S sensitive cells; R/exo, exosomes from H827R-7-1 resistant cells; PI, propidium iodide; H827S, gefitinib-susceptible HCC827 lung cancer cells.

As presented in Fig. 3B, compared to $\mathrm{H} 827 \mathrm{~S}+\mathrm{NC}$ siRNA+S/exo group (100\%), cell viability was decreased in $\mathrm{H} 827 \mathrm{~S}+\mathrm{NC}$ siRNA+S/exo+gefitinib group $(57.5 \pm 1.6 \%)$. However, H827S+NC siRNA+R/exo+gefitinib group had elevated cell viability $(67.0 \pm 1.1 \%)$, compared to $\mathrm{H} 827 \mathrm{~S}+\mathrm{NC}$ siRNA+S/exo+gefitinib group. Following miR-21 knockdown, drug resistance was partially reversed; cell viability decreased in $\mathrm{H} 827 \mathrm{~S}$ cells pretreated with R/exo and stimulated with gefitinib $(61.3 \pm 0.9 \%)$.

The result of apoptosis assay (Fig. 3C and D) was similar with result of CCK-8 experiment. H827S+NC siRNA+S/exo+gefitinib group exhibited greater apoptosis $(44.0 \pm 0.70 \%)$ compared with H827S+NC siRNA+S/exo group $(6.1 \pm 2.0 \%)$. H827S+NC siRNA+R/exo+gefitinib group had a significantly lower apoptosis rate $(32.4 \pm 1.21 \%)$. Transfection of the miR-21 inhibitor sensitized H827S cells that were pretreated with R/exo and underwent stimulation with gefitinib, with an increased apoptosis rate $(40.0 \pm 1.7 \%)$.

Exosomes transmit resistance to gefitinib by activating the Akt signaling pathway. Akt is an important downstream signaling pathway of EGFR and Akt activation is associated with the prognosis of patients with lung cancer (19). To further investigate the underlying mechanism of gefitinib resistance transmitted by R/exo, the expression of p-Akt was measured using western blot analysis (Fig. 4). Gefitinib treatment notably downregulated p-Akt expression in the S/exo treated group compared with the control. However, R/exo pretreatment elevated p-Akt levels and promoted Akt activation compared with the S/exo treated group. However, miR-21 inhibition reduced p-Akt expression and blocked Akt activation in cells pretreated with R/exo.

\section{Discussion}

Gefitinib is a major chemotherapeutic agent used to treat lung cancer and significantly improves the overall survival rate of patients with cancer that harbor somatic mutations in the EGFR gene (2). However, acquired resistance to gefitinib remains a major problem in cancer treatment and limits treatment efficacy. At present, the underlying mechanisms of acquired resistance to gefitinib are not fully understood.

Exosomes have emerged as important messengers of cellular communication in normal physiological processes and diseases, including liver and neurodegenerative diseases, as well as the development and progression of cancer $(20,21)$. In addition, studies have identified a close association between exosomes and drug resistance in various types of cancer, 

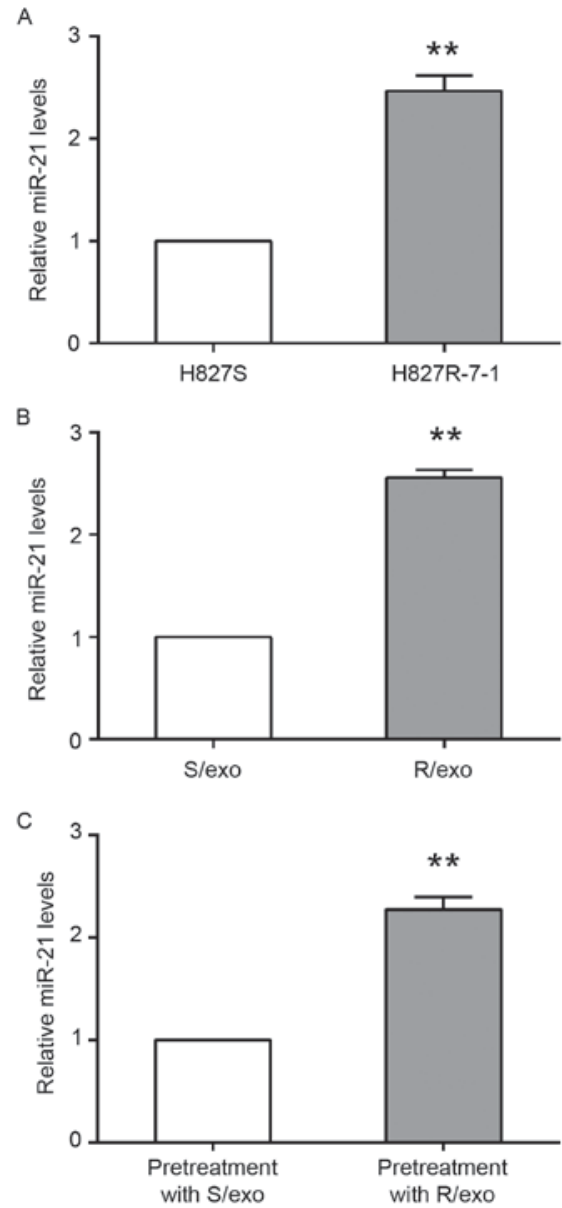

Figure 2. Expression of miR-21 in experimental groups. mRNA was extracted from (A) H827R-7-1 and H827S cells, (B) R/exo and S/exo and (C) R/exo-treated and S/exo treated cells and analyzed by reverse transcription-quantitative polymerase chain reaction. miR-21 was upregulated by 2.46 \pm 0.15 -fold in H827R-7-1 cells compared with H827S cells. miR-21 was upregulated by $2.56 \pm 0.08$-fold in R/exo compared with S/exo. miR-21 was upregulated by $2.28 \pm 0.12$-fold in R/exo treated $\mathrm{H} 827 \mathrm{~S}$ cells compared with S/exo treated cells. The fold change in miR-21 levels have been normalized to U6 levels. ${ }^{* * *} \mathrm{P}<0.01$ vs. the control. mi, micro; S/exo, exosome from H827S sensitive cells; R/exo, exosomes from H827R-7-1 resistant cells; H827R-7-1, gefitinib-resistant HCC827 lung cancer cells; H827S, gefitinib-susceptible HCC827 lung cancer cells.

including breast $(9,22)$, ovarian (23) and prostate (24) cancer, which suggests that drug resistance in lung cancer cells may be acquired via exosomes. Cisplatin exposure may increase exosome secretion and the interaction of these secreted exosomes with other cancer cells may increase the resistance of A549 cells to cisplatin (10). Exosomes derived from gefitinib-treated lung cancer cells decreased the anti-tumor effects of cisplatin, whereas exosomes derived from cisplatin-treated lung cancer cells did not significantly alter the antitumor effects of gefitinib (25). These results suggest that the inhibition of exosome secretion may be a helpful strategy to overcome drug resistance. In he present study, cell viability was decreased in the $\mathrm{H} 827 \mathrm{~S}+\mathrm{NC}$ siRNA+S/exo+gefitinib group, indicating the inhibitory effect of gefitinib. The H827S+NC siRNA+R/exo+gefitinib group exhibited elevated cell viability and a decreased apoptosis rate compared to the $\mathrm{H} 827 \mathrm{~S}+\mathrm{NC}$ siRNA+S/exo+gefitinib group, suggesting that gefitinib resistance in lung cancer cells may be acquired via exosomes. To the best of our knowledge, the present study was the first to demonstrate that exosomes from gefitinib-resistant cells confer drug resistance in lung cancer cells, as it was observed that R/exo-treated H827S cells lost their sensitivity to gefitinib.

Exosomes transfer RNAs and proteins to mediate communication among cancer cells and exosome-mediated miRNA transfer may be a novel method of gene transfer among cells (26). Previous in vitro and in vivo studies have indicated that miR-21 is frequently overexpressed in various human tumors and in cancer cell lines, and promotes oncogenesis, suggesting that it is an onco-miR $(27,28)$. Additionally, the association between miR-21 and drug resistance has been investigated and high levels of miR-21 were detected in 5-fluorouracil-resistant human pancreatic, cisplatin-resistant ovarian, doxorubicin-resistant breast and cisplatin-resistant neuroblastoma cancer cells (15,29-31). In a previous study, 20 patients with advanced NSCLC with the EGFR 19 deletion were treated with first-line EGFR-TKIs and divided into two groups: A EGFR-TKI-resistant group and a EGFR-TKI-sensitive group (32). The expression of plasma miR-21 was significantly higher in the EGFR-TKI resistant group compared with the EGFR-TKI-sensitive group as determined by a TaqMan low-density array (32). Li et al reported that miR-21 was overexpressed in the EGFR-TKI resistant cell line PC9R compared with the PC9 non-resistant cell line, that miR-21 expression was negatively associated with the expression of PTEN, and that programmed cell death protein 4 was positively associated with the phosphatidylinositol 3-kinase (PI3K)/Akt signaling pathway (18). Additionally, the inhibition of miR-21 induced apoptosis in the PC9R cell line and inhibited miR-21, while miR-21 antisense oligo nucleotide (ASO) suppressed tumor growth in nude mice treated with EGFR-TKI (18). Shen et al (33) revealed that high miR-21 expression indicated a poor TKI clinical response and a shorter overall survival rate. miR-21 expression was upregulated in PC-9 gefitinib resistant cells (PC-9/GR) compared with PC-9 cells and miR-21 knockdown markedly restored gefitinib sensitivity in PC-9/GR cells (33). Similar to previous studies, the results of the present investigation revealed that miR-21 expression was elevated in gefitinib-resistant lung cancer cells. miR-21 expression was increased in exosomes from H827R-7-1 cells and R/exo-stimulated H827S cells. It was considered that miR-21 in H827R-7-1 was released into exosomes and transported into $\mathrm{H} 827 \mathrm{~S}$ cells via exosomes, thereby changing the sensitivity of H827S cells to gefitinib. Following miR-21 knockdown, drug resistance was partially reversed; cell viability decreased and apoptosis rate increased in $\mathrm{H} 827 \mathrm{~S}$ cells pretreated with R/exo and stimulated with gefitinib. These results indicate that miR-21 serves a crucial function in gefitinib resistance inferred by exosomes.

Akt is a downstream mediator of PI3K, which serves a central role in tumorigenesis. EGFR-TKIs primarily inhibit the downstream signaling pathway activity of EGFR via the PI3K/Akt signaling pathway, thereby inhibiting cell proliferation and invasion, as well as inducing apoptosis (34). The suppression of the Akt signaling pathway may preserve gefitinib resistance in NSCLC cell lines (35). It has been demonstrated that miR-21 positively regulates the PI3K/Akt signaling pathway $(18,36,37)$. miR-21 suppresses tumor cell migration 

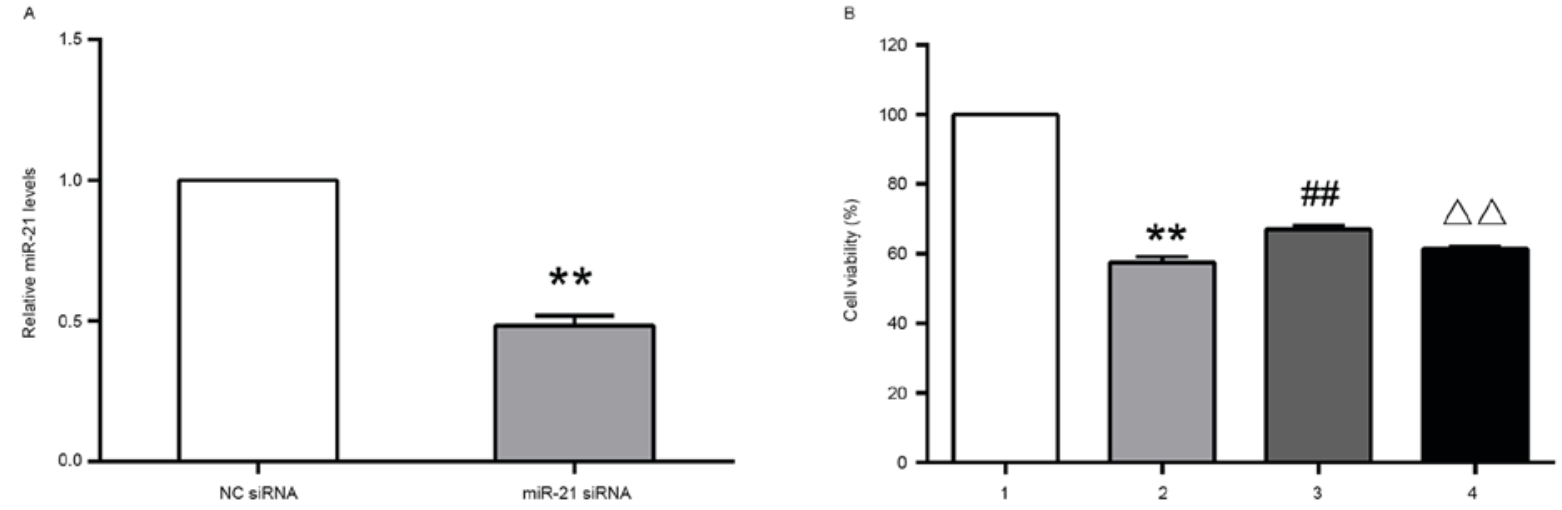
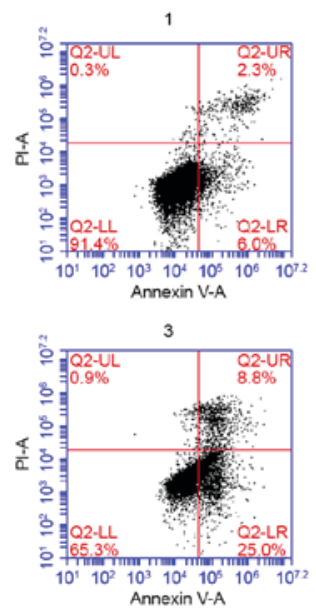

1. $H 827 \mathrm{~S}+\mathrm{NC}$ siRNA+S/exo

3. $H 827 S+N C$ siRNA+R/exo+gef tinib
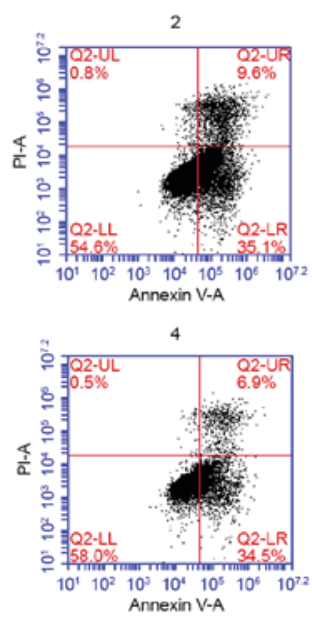

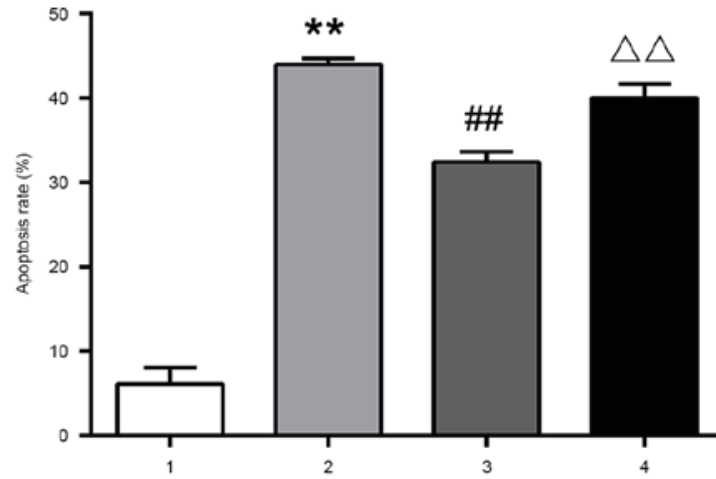

2. $\mathrm{H} 827 \mathrm{~S}+\mathrm{NC}$ siRNA+S/exo+gefitinib

4. H827S+miR-21 siRNA+R/exo+geftinib

Figure 3. Effect of miR-21 on exosome-induced gefitinib resistance. (A) H827 cells were prepared for reverse transcription-quantitative polymerase chain reaction analysis following transient transfection with NC siRNA or miR-21 siRNA. Transfected H827S cells were then treated with S/exo or R/exo for $24 \mathrm{~h}$ and gefitinib for a further $48 \mathrm{~h}$. Treated cells were harvested for a (B) cell viability assay and (C) flow cytometry, which was used to determine the (D) apoptosis rate. Significant differences are indicated by different symbols. ${ }^{* *} \mathrm{P}<0.01 \mathrm{vs} .1 ;{ }^{\# \#} \mathrm{P}<0.01$ vs. $2 ;{ }^{\Delta \Delta} \mathrm{P}<0.01 \mathrm{vs}$. 3. mi, micro; NC, negative control; si, small interfering; S/exo, exosomes from H827S sensitive cells; R/exo, exosomes from H827R-7-1 resistant cells; PI, propidium iodide; H827S, gefitinib-susceptible HCC827 lung cancer cells.

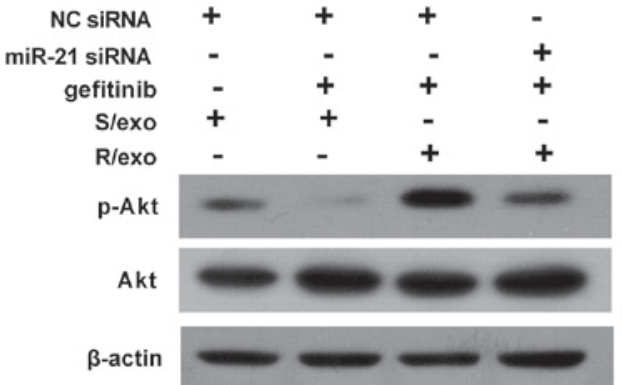

Figure 4. Expression of Akt and p-Akt in H827S cells. Following $24 \mathrm{~h}$ incubation with either NC siRNA or miR-21 siRNA, H827S cells were incubated with either S/exo or R/exo for $24 \mathrm{~h}$ and incubated for a further $48 \mathrm{~h}$ with gefitinib. Cells were lysed and subjected to western immunoblot analysis with anti-Akt or anti-p-Akt antibodies. Akt, protein kinase B; p-, phosphorylated; NC, negative control; si, small interfering; mi, micro; S/exo, exosome from H827S sensitive cells; R/exo, exosomes from H827R-7-1 resistant cells; H827S, gefitinib-susceptible HCC827 lung cancer cells.

and invasion by reducing PI3K/Akt signaling and reversing the epithelial-mesenchymal transition in breast cancer (36). miR-21 also modulates the radiosensitivity of cervical cancer by inhibiting autophagy via the Akt-mTOR signaling pathway (37). Furthermore, miR-21 induces Akt phosphorylation and activates the Akt signaling pathway, thereby leading to the acquired resistance to EGFR-TKIs in the NSCLC cell lines (18). In the present study, p-Akt expression was downregulated by gefitinib treatment and miR-21 silencing in H827S cells, suggesting that miR-21 knockdown may ameliorate the exosome-mediated activation of Akt and increase the sensitivity of $\mathrm{H} 827 \mathrm{~S}$ cells to gefitinib.

In conclusion, the results of the present study revealed that exosomes released by gefitinib-resistant lung cancer cells decreased the sensitivity of gefitinib-sensitive cells. The present study indicates that miR-21 is a critical mediator in exosome-induced drug resistance. The inhibition of exosome formation and release may be developed as a novel therapeutic strategy of addressing gefitinib resistance in patients with lung cancer in the future.

\section{Acknowledgements}

The present study was supported by the general program of the Department of Health in Jiangsu province (grant no. H201410), 
the National Natural Science Foundation of China (grant no. 81402483) and by the Natural Science Foundation of Jiangsu Province (grant no. BK20141016).

\section{References}

1. Chen W, Zheng R, Baade PD, Zhang S, Zeng H, Bray F, Jemal A, Yu XQ and He J: Cancer statistics in China, 2015. CA Cancer J Clin 66: 115-132, 2016.

2. Maemondo M, Inoue A, Kobayashi K, Sugawara S, Oizumi S, Isobe $\mathrm{H}$, Gemma A, Harada M, Yoshizawa H, Kinoshita I, et al: Gefitinib or chemotherapy for non-small-cell lung cancer with mutated EGFR. N Engl J Med 362: 2380-2388, 2010.

3. Thatcher N, Chang A, Parikh P, Rodrigues Pereira J, Ciuleanu T, von Pawel J, Thongprasert S, Tan EH, Pemberton K, Archer V and Carroll K: Gefitinib plus best supportive care in previously treated patients with refractory advanced non-small-cell lung cancer: Results from a randomised, placebo-controlled, multicentre study (Iressa Survival Evaluation in Lung Cancer). Lancet 366: 1527-1537, 2005.

4. Mok TS, Wu YL, Thongprasert S, Yang CH, Chu DT, Saijo N, Sunpaweravong P, Han B, Margono B, Ichinose Y, et al: Gefitinib or carboplatin-paclitaxel in pulmonary adenocarcinoma. N Engl J Med 361: 947-957, 2009.

5. Suda K, Murakami I, Katayama T, Tomizawa K, Osada H, Sekido Y, Maehara Y, Yatabe Y and Mitsudomi T: Reciprocal and complementary role of MET amplification and EGFR $\mathrm{T} 790 \mathrm{M}$ mutation in acquired resistance to kinase inhibitors in lung cancer. Clin Cancer Res 16: 5489-5498, 2010.

6. van der Pol E, Böing AN, Harrison P, Sturk A and Nieuwland R: Classification, functions, and clinical relevance of extracellular vesicles. Pharmacol Rev 64: 676-705, 2012.

7. Katakowski M, Buller B, Zheng X, Lu Y, Rogers T, Osobamiro O, Shu W, Jiang F and Chopp M: Exosomes from marrow stromal cells expressing miR-146b inhibit glioma growth. Cancer Lett 335: 201-204, 2013.

8. Vlassov AV, Magdaleno S, Setterquist R and Conrad R: Exosomes: Current knowledge of their composition, biological functions, and diagnostic and therapeutic potentials. Biochim Biophys Acta 1820: 940-948, 2012.

9. Lv MM, Zhu XY, Chen WX, Zhong SL, Hu Q, Ma TF, Zhang J, Chen L, Tang JH and Zhao JH: Exosomes mediate drug resistance transfer in MCF-7 breast cancer cells and a probable mechanism is delivery of P-glycoprotein. Tumour Biol 35: 10773-10779, 2014.

10. Xiao X, Yu S, Li S, Wu J, Ma R, Cao H, Zhu Y and Feng J: Exosomes: Decreased sensitivity of lung cancer A549 cells to cisplatin. PloS One 9: e89534, 2014

11. Liu SW, Cao HX, Wu JZ, Ma R, Jing CW, Wang Z and Feng JF: Difference of miRNA-7 expression in the non-small cell lung cancer with different sensitivity to gefitinib and their clinical significance. Chin J Surg Onco 7: 74-77, 2015.

12. Livak KJ and Schmittgen TD: Analysis of relative gene expression data using real-time quantitative PCR and the 2(-Delta Delta C(T)) method. Methods 25: 402-408, 2001.

13. He L and Hannon GJ: MicroRNAs: Small RNAs with a big role in gene regulation. Nat Rev Genet 5: 522-531, 2004.

14. Li S, Liang Z, Xu L and Zou F: MicroRNA-21: A ubiquitously expressed pro-survival factor in cancer and other diseases. Mol Cell Biochem 360: 147-158, 2012.

15. Wang ZX, Lu BB, Wang H, Cheng ZX and Yin YM: MicroRNA-21 modulates chemosensitivity of breast cancer cells to doxorubicin by targeting PTEN. Arch Med Res 42: 281-290, 2011.

16. Yang SM, Huang C, Li XF, Yu MZ, He Y and Li J: miR-21 confers cisplatin resistance in gastric cancer cells by regulating PTEN. Toxicology 306: 162-168, 2013.

17. Ziyan W and Yang L: MicroRNA-21 regulates the sensitivity to cisplatin in a human osteosarcoma cell line. Ir J Med Sci 185 85-91, 2016.

18. Li B, Ren S, Li X, Wang Y, Garfield D, Zhou S, Chen X, Su C, Chen M, Kuang P, et al: MiR-21 overexpression is associated with acquired resistance of EGFR-TKI in non-small cell lung cancer. Lung Cancer 83: 146-153, 2014.

19. Tang JM, He QY, Guo RX and Chang XJ: Phosphorylated Akt overexpression and loss of PTEN expression in non-small cell lung cancer confers poor prognosis. Lung Cancer 51: 181-191, 2006.

20. Masyuk AI, Masyuk TV and Larusso NF: Exosomes in the pathogenesis, diagnostics and therapeutics of liver diseases. J Hepatol 59: 621-625, 2013.
21. Vella LJ, Sharples RA, Nisbet RM, Cappai R and Hill AF: The role of exosomes in the processing of proteins associated with neurodegenerative diseases. Eur Biophys J 37: 323-332, 2008

22. Yu DD, Wu Y, Zhang XH, Lv MM, Chen WX, Chen X, Yang SJ, Shen H, Zhong SL, Tang JH and Zhao JH: Exosomes from adriamycin-resistant breast cancer cells transmit drug resistance partly by delivering miR-222. Tumour Biol 37: 3227-3235, 2016.

23. Au Yeung CL, Co NN, Tsuruga T, Yeung TL, Kwan SY, Leung CS, Li Y, Lu ES, Kwan K, Wong KK, et al: Exosomal transfer of stroma-derived miR 21 confers paclitaxel resistance in ovarian cancer cells through targeting APAF1. Nat Commun 7: 11150, 2016.

24. Corcoran C, Rani S, O'Brien K, O'Neill A, Prencipe M, Sheikh R, Webb G, McDermott R, Watson W, Crown J and O'Driscoll L: Docetaxel-resistance in prostate cancer: Evaluating associated phenotypic changes and potential for resistance transfer via exosomes. PloS One 7: e50999, 2012.

25. Li XQ, Liu JT, Fan LL, Liu Y, Cheng L, Wang F, Yu HQ, Gao J, Wei W, Wang H and Sun GP: Exosomes derived from gefitinib-treated EGFR-mutant lung cancer cells alter cisplatin sensitivity via up-regulating autophagy. Oncotarget 7: 24585-24595, 2016.

26. Valadi H, Ekström K, Bossios A, Sjöstrand M, Lee JJ and Lötvall JO: Exosome-mediated transfer of mRNAs and microRNAs is a novel mechanism of genetic exchange between cells. Nat Cell Biol 9: 654-659, 2007.

27. Capodanno A, Boldrini L, Proietti A, Alì G, Pelliccioni S Niccoli C, D'Incecco A, Cappuzzo F, Chella A, Lucchi M, et al: Let-7g and miR-21 expression in non-small cell lung cancer: Correlation with clinicopathological and molecular features. Int J Oncol 43: 765-774, 2013.

28. Liu ZL, Wang H, Liu J and Wang ZX: MicroRNA-21 (miR-21) expression promotes growth, metastasis, and chemo- or radioresistance in non-small cell lung cancer cells by targeting PTEN. Mol Cell Biochem 372: 35-45, 2013.

29. Wei X, Wang W, Wang L, Zhang Y, Zhang X, Chen M, Wang F, Yu J, Ma Y and Sun G: MicroRNA-21 induces 5-fluorouracil resistance in human pancreatic cancer cells by regulating PTEN and PDCD4. Cancer Med 5: 693-702, 2016.

30. Echevarría-Vargas IM, Valiyeva F and Vívas-Mejia PE: Upregulation of miR-21 in cisplatin resistant ovarian cancer via JNK-1/c-Jun pathway. PloS One 9: e97094, 2014.

31. Chen Y, Tsai YH, Fang Y and Tseng SH: Micro-RNA-21 regulates the sensitivity to cisplatin in human neuroblastoma cells. J Pediatr Surg 47: 1797-1805, 2012.

32. Wang S, Su X, Bai H, Zhao J, Duan J, An T, Zhuo M, Wang Z, $\mathrm{Wu} \mathrm{M}, \mathrm{Li} \mathrm{Z}$, et al: Identification of plasma microRNA profiles for primary resistance to EGFR-TKIs in advanced non-small cell lung cancer (NSCLC) patients with EGFR activating mutation. J Hematol Oncol 8: 127, 2015.

33. Shen H, Zhu F, Liu J, Xu T, Pei D, Wang R, Qian Y, Li Q, Wang L, Shi Z, et al: Alteration in Mir-21/PTEN expression modulates gefitinib resistance in non-small cell lung cancer. PloS One 9: e103305, 2014

34. Chang F, Lee JT, Navolanic PM, Steelman LS, Shelton JG, Blalock WL, Franklin RA and McCubrey JA: Involvement of PI3K/Akt pathway in cell cycle progression, apoptosis, and neoplastic transformation: A target for cancer chemotherapy. Leukemia 17: 590-603, 2003.

35. Li H, Schmid-Bindert G, Wang D, Zhao Y, Yang X, Su B and Zhou C: Blocking the PI3K/AKT and MEK/ERK signaling pathways can overcome gefitinib-resistance in non-small cell lung cancer cell lines. Adv Med Sci 56: 275-284, 2011.

36. Yan LX, Liu YH, Xiang JW, Wu QN, Xu LB, Luo XL, Zhu XL, Liu C, Xu FP, Luo DL, et al: PIK3R1 targeting by miR-21 suppresses tumor cell migration and invasion by reducing $\mathrm{PI} 3 \mathrm{~K} / \mathrm{AKT}$ signaling and reversing EMT, and predicts clinical outcome of breast cancer. Int J Oncol 48: 471-484, 2016.

37. Song L, Liu S, Zhang L, Yao H, Gao F, Xu D and Li Q: MiR-21 modulates radiosensitivity of cervical cancer through inhibiting autophagy via the PTEN/Akt/HIF-1 $\alpha$ feedback loop and the Akt-mTOR signaling pathway. Tumour Biol 37: 12161-12168, 2016.

This work is licensed under a Creative Commons Attribution-NonCommercial-NoDerivatives 4.0 International (CC BY-NC-ND 4.0) License. 